\title{
Organising Principles for the Internationalization of Higher Education
}

\author{
Martin HENSON \\ University of Essex, Colchester, UK \\ martin.henson@khozama.co.uk \\ Irina Bogdana PUGNA \\ Academia de Studii Economice București, România \\ irina.pugna@cig.ase.ro
}

\begin{abstract}
The importance of internationalization, as a part of an institutional higher-education strategy cannot be overstated. In this paper we provide a mechanism for organizing a Higher Education Institution's internationalization strategy, recognizing that it is globalization that is forcing higher education institutions to internationalize. We briefly discuss and evaluate existing approaches and provide a new model and taxonomy for organizing strategic responses to higher education globalization in more detail. This model offers a classification scheme suitable for a variety of higher education institutions wherever located at different stages of their development.
\end{abstract}

Keywords: Higher Education, Internationalization, Globalization, Strategy

\section{Introduction}

It is hard to overestimate the current importance of internationalization, as a part of an institutional higher-education (HE) strategy. In this paper we provide a mechanism for organizing a Higher Education Institution's (HEI's) internationalization strategy, recognizing that it is globalization that is forcing HEIs to internationalize. Specifically, we are interested in supporting HEIs to find appropriate responses to the challenges of globalization that sensibly align with the HEI's own context.

The next section starts by providing the context and explaining the background of higher education internationalization, and then, in Section 3, we discuss some of the difficulties faced by HEIs in developing their international strategies. We then look at some established approaches and a new taxonomy and model for organizing a response to HE globalization, offering a classification scheme suitable for a variety of higher education institutions wherever located at different stages of their development. In Section 4 we briefly look at a classifications that are based variously on: location, relationships, and approach. Finally, we introduce, and discuss in detail, a fourth, which is based on the relative complexity of the partnership arrangements. We draw some conclusions in Section 5, followed by our references to the literature.

\section{The Global Context}

Our point of departure is to identify external HE opportunities offered by globalization as the key to organizing an internal response by an HEI: its internationalization strategy.

Almost as important is a recognition that - in fact - HEIs are not lagging behind (for example) private industry in taking internationalization seriously. Indeed, as we will see, they may be 
thought of as leaders. A major study of internationalization [Ghemawat, 2011] notes that in the US the number of internationalized companies was vanishingly small, as was their international workforce (though the picture is a little more encouraging elsewhere [Hanf \& Pall, 2009]). Compare this with [HESA1, 2019] which shows over 40\% international academics in STEM subjects in the UK in 2015-6. Student numbers show a similar profile: for example, the proportion of international students in the UK has remained steady over the last five years (at around 20\%) with a proportion a little over 50\% at the postgraduate level [HESA2, 2019]. With this level of global penetration, there may already be good reason to wonder whether the notions of external globalization and internal internationalization have disintegrated entirely in the world of HE.

However, there is a strong recognition that changes - especially those connected with internationalization - are indeed happening and are important. For example: "An academic revolution has taken place in higher education in the past half century marked by transformations unprecedented in scope and diversity. Comprehending this on-going and dynamic process while being in the midst of it is not an easy task" [Altbach et al, 2009] And: "... going it alone is increasingly difficult, and ... partnerships ... build capacity and strength that few institutions can muster on their own. Paradoxically, 'cooperation redefines the space in which higher education competes'." [Kinser \& Green, 2009]

So we may be in danger of underestimating the complexities of the global context and the internal complexities of our HEIs. Let us now examine these.

\section{The Strategic Context}

Almost all HEIs are engaging in some form or another in a variety of international activities - though these may be limited in scope and they may lack any kind of strategic direction. On the other hand, those HEIs with an international strategy often state rather vague ambitions that lack a secure basis. For example, "Develop and embed a consistent understanding of and approach to internationalisation across the University" (reference to this has been deliberately omitted) is a sound ambition - but in the absence of its addressing a very clear challenge, it is somewhat unclear what its implementation will involve. We strongly believe that a realistic strategy should be challenge-based - and so tied securely to each HEI's current circumstances. As such, we cannot (indeed, should not) try to give guidance regarding specific strategic ambitions - but we believe that we can give some organizing principles that can be usefully adapted according to specific challenges that an HEI faces. First, though, we should be clear about the terms we are employing and how much they differ from their use in other, perhaps better understood, contexts.

\section{Globalization}

If we were discussing commerce, we would stress the global pull factors of non-national markets and the push factors from hitting limits within national markets [Hanf \& Pall, 2009]. There are some analogies here for HEIs: where there are regulatory limits on student numbers, and decreasing state support for national students, similar push factors may be present. Similarly, a lack of high-class HE coupled with increased purchasing power in some non-national jurisdictions may imply similar pull factors.

However, this analogy focuses only on financial comparisons - and HEIs are committed to other value outcomes: notably the education, scholarship, research, and 
engagement with (contributions to) the community. These complicate the global picture for HE immensely.

\section{Internationalization}

Here we will concentrate on the contrast between in-facing and out-facing internationalization [Welch \& Luostarinen, 1993]. In commercial contexts, the former includes, for example, sourcing raw materials from overseas. The latter includes, for example, exporting products to international markets or locating production overseas. Again, there are some direct analogies: recruiting international faculty is in-facing while branch campuses are out-facing.

Again, this misses much complexity in the HE context. The education of international students looks suspiciously like importing raw materials and exporting finished products with the in/out-facing flows covariant with the geographic movement. However, in the HE context the situation is contravariant: the student is imported but the transaction is education (which is actually exported - the student is the container!).

Moreover, because there are other value outcomes, there are additional covariant situations: Incoming students contribute directly to the local context, providing representation (as ambassadors for their alma mater) facilitating access in their home markets, and contributing to the "internationalization" component of league table calculations.

Finally, there is what is known as academic arbitrage (a term described in [Colcanis \& Strauss, 2010]) which notes that resources in one market have a different (a higher) value in another. Access to expensive equipment, particular kinds of academic expertise, and geographical access, are examples. There are similar examples in commercial markets - but because one player is often much more powerful than the other, this is usually one sided; in the HE context the situation is more usually mutually beneficial.

All these considerations serve to demonstrate that the complexities of HEI missions (typically multi-faceted with tensions and synergies between the components), and the value outcomes implied, make notions of globalization and internationalization quite different from those of simpler commercial organizations. Negotiating this complexity may be aided by conceptual tools that support the organization of multiple options. We now briefly discuss some existing approaches and introduce a new model in more detail.

\section{A Taxonomy for Internationalization}

Some who have analyzed this in the past have distinguished simply between internationalization at home and internationalization abroad [Koutsantoni, 2006]. For example, at home, we may be interested in internationalizing the curriculum, providing opportunities for foreign language learning, allowing inward student mobility, hosting summer schools, undertaking internationally informed research, and offering tailored approaches and services to support international students. In contrast, abroad, we might be interested in outward-facing student and faculty mobility, alumni activities, joint academic appointments, internationally engaged research, franchised academic programs, regional offices, and branch campuses. 
This is a useful way to divide the territory, though - structurally - it is relatively crude; the main weakness being differences in the type and complexity of activities that fall on one or other side of the divide.

We might, for example, extend this binary model with internationalization together or better: consider distinguishing between symmetric and asymmetric relationships. Mobility programs are often symmetric, whereas franchise and validation arrangements are essentially asymmetric. However, distortions may appear here for quite unexpected reasons. For example, joint degrees (e.g. [EM, 2019]) look symmetric - but if the financial underpinnings differ between partners (e.g. fee-paying students in the UK versus the free education that is offered in Germany), the same activity may turn out to be positively asymmetric.

Looking at internationalization in terms of approach is another interesting possibility. Here we are encouraged to consider an HEI's whole approach across all its international activities. In [Knight, 2010] the author considers Activity, Outcomes, Rationales, Process, Ethos, and Cross-border. The first three focus on the activities themselves, their intended consequences, and their drivers. The Process approach considers how internationalization integrates with other distinct strategic ambitions within the HEI. The last two - roughly correspond to internationalization and home and abroad (especially the more ambitious activities) as discussed above.

Of the six, the Outcomes and Rationale approaches do provide an opportunity to sensibly align with globalization's imperatives, and the Process approach sensibly asks that internationalization be considered as wholly integrated into the broader strategy - rather than being treated as an extra (distinct) feature.

Based on these existing ideas, and their advantages and disadvantages, we propose a two-dimensional model that considers placing the complexity of activities along one axis, and the complexity of partnerships along the other.

Figure 1, below, shows four cells. However, it is important to note that this is not a generalization of the two-valued models discussed above. Crucially, similar activities may appear in more than one cell - as we later discuss.

\section{Type 1 - Narrowly Based Bilateral Partnerships}

Type 1 are bilateral with a narrow focus. These often center on exchange programs. These are sometime symmetric and sometimes asymmetric, typically involving exchange programs, opportunities for students to study-abroad, internships, summer schools, and opportunities for volunteering. In addition, we often see faculty exchange programs too.

The joint degree is another type of narrow bilateral partnership when it involves just two collaborators.

Type 1 activities do not form part of a broader and more comprehensive relationship. Consequently, it is not a design flaw that these simple academic-to-academic relationships most often lack strategic oversight - it is almost certainly an appropriate tactical approach to take, and they are often really valuable for the institution. 


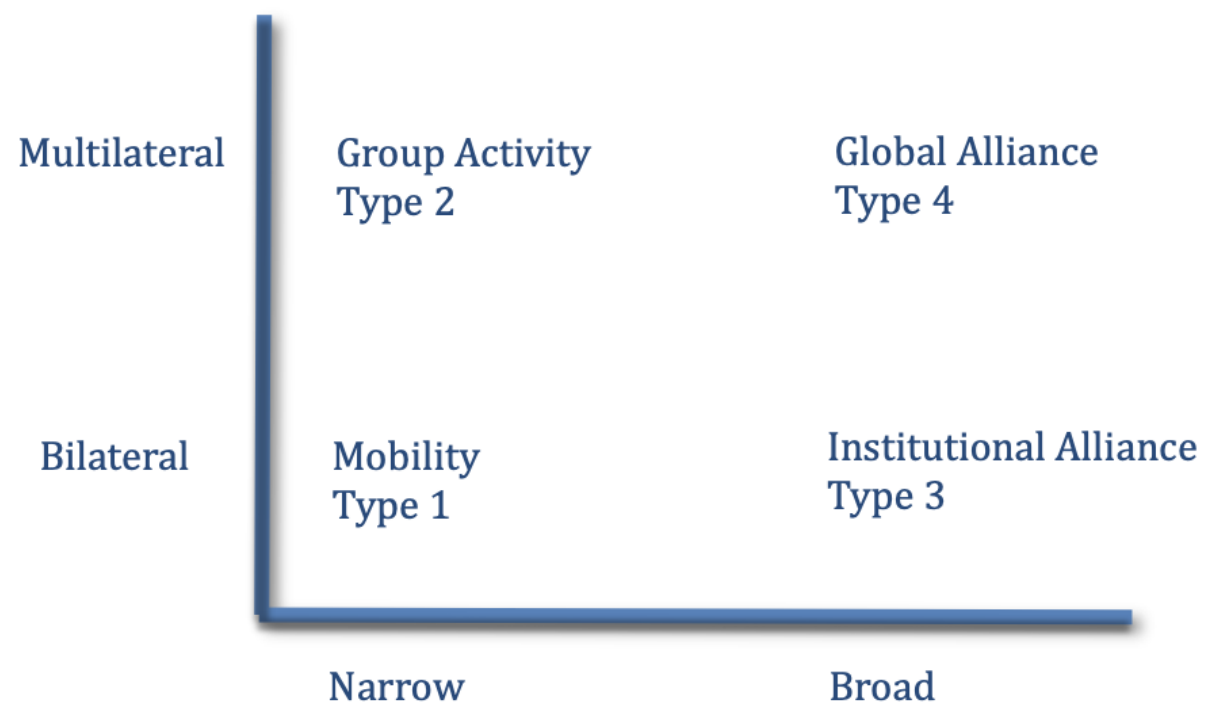

Figure 1

Similarly, HEIs with a good international student mobility will have numerous bilateral agreements. Together these probably represent the fulfillment of a strategic aim: to improve academic performance and the work readiness of students through an international experience. The details of individual agreements within the set are tactical rather than strategic. We discuss this more in section 4.5 , below.

\section{Type 2 - Narrowly Based Multi-lateral Partnerships}

Type 2 relationships will be familiar to most HEIs. Here we may think of research groups which have established productive collaborations other research groups in other countries. Quite often these will be supported by grants from national or international agencies.

Type 2 relationships include, academic programs offered by a set of universities . We call these "internationally engaged" degree programs. The Global Studies Programme offered by the University of Freiburg and its partners is a good exemplar: "The Global Studies Programme is a two-year Master programme initiated in 2002 followed by an optional PhD initiated in 2008. The mission of the programme is to study social sciences in various cultures and regions focusing on the global South. It is conducted jointly by the University of Freiburg, the University of Cape Town, FLACSO-Argentina (Buenos Aires), Chulalongkorn University (Bangkok) and the Jawaharlal Nehru University (New Delhi). Each institution belongs to the best in its region." [GSP, 2019].

The Center for Urban Science and Progress (CUSP) involves New York University and six other higher education institutions from four countries, together with nine industry partners, and a number of civic and governmental entities. It creates critical mass and a focus for research and graduate study. Its focus lies on energy, infrastructure and public safety [Lawton et al, 2014].

CUSP offers a qualification in Applied Urban Science and Informatics. The partners also offer postgraduate themselves. An important feature is that students study at a number of different institutions in the course of their studies. CUSP is now developing its activities in 
research. It could be said to be moving towards a Type 4 relationship. Such relationships are described in Section 4.4, below.

\section{Type 3 - Broadly Based Bilateral Partnerships}

Partnerships of Type 3 are alliances between two HEIs involving multiple activities. One example is the partnership between the University of Warwick in the UK and Monash University in Australia [WMIA, 2019]. '...the partnership reveals a shift for the education sector. While it aims to deliver a seamless international experience for students, the advent of a range of jointly delivered degrees at both universities represents a departure from traditional educational partnerships and shows at least some of the hallmarks of cross-border

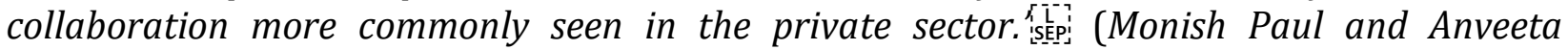
Shrivastava, Deloitte, Australian Financial Review, 2 April 2012)

These two institutions began started by investing financial resources into this joint venture. Partly because it was so new, they were able to obtain more funding from their governments. $£ 500 \mathrm{k}$ was awarded by the UK Engineering and Physical Sciences Research Council (EPSRC) under its 'Building Global Engagements' programme, the Australian Government provided $£ 66 \mathrm{k}$ for student exchanges, and Australian Research Council committed $£ 200 \mathrm{k}$ to set up joint initiatives in engineering.

The partnership involves: a PhD programme, research, student exchanges, faculty exchanges, other student activities, joint academic programs, and research over a number of subjects. They have also established a research journal for students.

Relationships such as these are very productive and differ substantially from the existing model of a HEI: they offer a significantly different way to address the challenges of HE globalization. Clearly, they set enormous difficulties for management and for governance more generally. This particular alliance, recognizing these potential difficulties, appointed a senior manager to oversee the partnership

\section{Type 4 - Broadly Based Multi-lateral Partnerships}

There are a growing number of these, the oldest of which is Universitas 21 [U21, 2019]. Here, a large number of institutions cooperate and do so over a broad range of activities. Universitas 21 currently comprises 27 members drawn from 17 countries and covers more than half a million students. It was founded in 1997 offers a range of collaborative education, undertakes joint research, engages in student exchanges, and operates as a "think-tank" on HE.

The universities collaborate on many levels, undergraduate and postgraduate research, and several hundred students a year participate in the student exchange programs, the U21 Student Mobility Programme. The management is so complex that a company U21pedagogica Ltd was set up to provide administration and quality assurance.

Other long-standing partnerships of this kind include the Worldwide Universities Network [WUN, 2019], the League of European Research Universities [LERU, 2019], and the International Alliance of Research Universities [IARU, 2019]. Each of these has a distinct profile and places emphasis on one or another activity. There are reasons to doubt the success of these groupings. The number of potential interactions grows very rapidly as partners are added but the resource available to control the breadth of the interactions, does 
not - and becomes diluted. Moreover, the differences between the various governance arrangements of the members are not insignificant.

As a result, Type 3 agreements, which focus on smaller groupings seem to be becoming more and more common.

\section{Critique}

PICBE | 790

This four-valued approach is different from the two-valued classification which we described earlier. Here, an something appears in a cell just in case it is considered alongside all activities with all partners. A study abroad agreement, for instance, occurs as Type 1 when there are that agreement has no other collaborator and when that collaborator shares no other activities - otherwise it would be found elsewhere in the model. This is an important feature - allowing us to evaluate the importance of an activity, strategically, in a context of related partners and mutual activities.

This model also helps us to navigate potential changes to the partnerships. We described in 4.2, a project that is changing over time from Type 2 to Type 4 . As relationships shift within the model, we are better able to anticipate and implement appropriate strategic changes.

If there is a weakness to our model, it may be connected with sets of related activities of Type 1 (and to some extent, Type 2). For example, as we discussed in section 4.1 above, the set of all bilateral student mobility agreements that an HEI has would form a natural type - but is not itself a partnership. Although the implementation of the individual agreements is essentially tactical, these nevertheless require strategic management. Likewise, an individual joint or double degree needs quality oversight - but a set of such degrees implies significant implications for quality management, planning and resourcing - and, thus, becomes a strategic concern.

We might, then, modify the matrix by including considerations from the Rationales and Process approaches that we discussed earlier. This would allow us to model sets of activities across dimensions that do not relate to partners.

\section{Conclusions}

We have demonstrated that the concepts of globalization and internationalization in higher education are different from - indeed more complex than - those we typically find in a commercial setting. This is a consequence of the multi-dimensional mission of most HEIs. These dimensions are subject to distinct drivers, globally. Consequently, they need separate consideration. Fundamentally, HE leads to several value outcomes that transcend the financial. It is therefore a real challenge to develop a useful international strategy that sensibly engages the global externalities. We have proposed a model for organizing these multiple opportunities. They recognize distinct modes of institutional interaction along two dimensions of complexity: the complexity of the partnerships, and the complexity of the activities.

We have not, however, discussed several key areas that need to be considered alongside the strategic. These include further discussion and analysis of issues concerning governance - which include the often strange (and often strained) dynamic between those who deliver the core value outcomes (the academics, students, ...) and those who have the responsibility to support them (the various professional services). In particular, among these 
services, are those covering quality monitoring and improvement. International activities raise many difficulties in this (and other professional) areas, and these are fundamental to the success of complex international activities. Investigating and analyzing this remains as future work.

\section{References}

Altbach, P. G., Reisberg, L. and Rumbley, L. E., Trends in Global Higher Education: Tracking an Academic Revolution, A Report Prepared for the UNESCO World Conference on Higher Education, 2009

Coclanis, P. A. and Strauss, R. P., Partnerships: an Alternative to Branch Campuses Overseas, Commentary, The Chronicle, 2010 http://chronicle.com/article/Partnerships-aDifferent-A/124286/ (accessed 31 January 2019)

EM - Erasmus Mundus Action 1 - Joint Programmes: https://eacea.ec.europa.eu/sites/20072013/erasmus-mundus-programme_en (accessed 31 January 2019)

Ghemawat, P., World 3.0: Global Prosperity and how to Achieve it, 2011

GSP - Global Studies Programme: https://www.gsp.uni-freiburg.de/programme (accessed 31 January 2019)

Hanf, J. H. and Pall, Z, Is retailing really unique? Insights into retail internationalization using business theories, 113th EAAE Seminar "A resilient European food industry and food chain in a challenging world", Crete, Greece, 2009

IARU - International Alliance of Research Universities: http://www.iaruni.org (accessed 31 January 2019)

Kinser, K. and Green, M. F., "The Power of Partnerships: A Transatlantic Dialogue”, American Council on Education, 2009

Koutsantoni, D. Internationalisation in the UK. Leadership Foundation for Higher Education, Briefing Papers. London: Leadership Foundation for Higher Education, 2006.

Knight, J., Internationalisation: Key Concepts and Elements, Article A1.1 of Internationalisation of Higher Education - An EUA/ACA Handbook, 2010

Lawton, W. et al, Horizon Scanning: what will higher education look like in 2020?, Observatory on Borderless Higher Education Report 12, 2014

LERU - League of European Research Universities: http://www.leru.org/index.php/public/home (accessed 31 January 2019)

U21 - Universitas 21: http://www.universitas21.com (accessed 31 January 2019)

WMIA - Warwick/Monash Institutional Alliance: https://warwick.ac.uk/global/mwa (accessed 31 January 2019)

Welch, L. S.; Luostarinen, R. (1993): Inward-Outward Connections in Internationalization, Journal of International Marketing, Vol. 1, No. 1, pp. 44-56

WUN - Worldwide Universities Network: http://www.wun.ac.uk (accessed 31 January 2019) HESA1- http://bit.ly/2HQzOal (accessed 31 January 2019)

HESA2 - http://bit.ly/2UBvUUa (accessed 31 January 2019) 